\title{
$\nabla$ \\ Ciberespaço: um passo da dança semiótica do universo
}

\author{
Vinícius Andrade Pereira \\ Universidade Federal do Rio de Janeiro
}

As coisas frias esquentam, quente

esfiria, imido seca, seco umedece.

Herácliro

\section{Introdução}

O Homem morreu ' e o humano nos escapa.

Toda tentativa de apreender a natureza humana, de apontar seus limites, de reduzi-la a uma essência tem se mostrado vã, revelando apenas mais uma das suas múltiplas faces. Assim foi com o bipede implume e racional de Aristóteles, com o humano-divino das tradições religiosas, com o sujeito-consciência de Descartes, com o sujeito transcendental de Kant, com o humano-macaco de Darwin, com o animal simbólico de Cassirer, ou com o neurótico de Freud.

Se uma humanidade essencial não pode ser revelada em nenhuma dessas perspectivas, o aparecimento de todas essas diferentes faces alargaram as dimensões do humano. Mas, quais faces ainda se mostrarão na contemporaneidade, tempos marcados pelo incremento das tecnologias cognitivas e comunicacionais? Que novas competências e rostos surgirão nesse trânsito por um espaço infotécnico?

Talvez agora, depois de todas essas frustradas tentativas de enclausuramento do humano numa única e excludente fisionomia, se esteja às vésperas da experiência de um diálogo entre todas as dimensões já reveladas, promovendo a aposta em um modelo de humanidade que, se pode ser caracterizada, seria por este escapamento ou deslizamento permanente quanto a uma essência.

Um homínida hipercomplexo que só se torna minimamente compreensivel quando delineiam-se contextos históricos e culturais nos quais possa ser surpreendido, admitindo-o sempre imbricado com outras produções expontâneas ou artificiais; enfim, como um mosaico poroso, aberto, incerto, fluido, caótico, passivel, porém, de produzir 
ordens e aprendizados que o mantém, por um certo tempo, vivo e minimamente orientado diante do inesperado e do estranho. ${ }^{2}$

O que aqui se conjectura é a possibilidade de se pensar o humano como um híbrido animal-tecnologia, que desde o seu aparecimento sobre a Terra traz como estigma a invenção permanente de si, afetando o seu meio e sendo afetado e constituído por este mesmo meio, deixando, ao longo da sua jornada, restos e tesouros que, ora se denomina cultura, ora tecnologia, ambos constituindo as realidades que permeiam a própria existência humana.

É assim que se pode enxergar o cenário contemporâneo, onde as tecnologias são (re)inventadas com tamanha velocidade que os efeitos sobre uma humanidade sempre volátil e cambiante nem sempre podem ser apreendidos na mesma velocidade. E diante do desconhecido, ou melhor, do ainda não conhecido, sente-se apreensão, medo mes$\mathrm{mo}^{3}$; ou ao contrário, faz-se apostas de ganhos e lucros. ${ }^{4}$

Talvez, nos dias de hoje, possa-se salientar que o que há de mais radical, quando se compara esta com outras realidades, seja a idéia de um novo espaço, entendido como virtual, já amplamente conhecido com o nome de Ciberespaço. Vem desta singular zona espacial e temporal promovida pelas chamadas novas tecnologias a novidade para 0 que se pode chamar de uma recente experiência de habitação no mundo para o humano. Ou seja, mantendo os termos das reflexões iniciais deste texto, vem do Ciberespaço a possibilidade de um novo exercicio humano. Lembre-se, um exercício nem mais verdadeiro nem definitivo que aqueles tantos que o antecederam, apenas um outro exercício, uma outra face que se desvela.

A partir dessas considerações iniciais, pode-se anunciar a proposta deste texto:

1. Analisar aspectos gerais de como têm sido apresentados o Ciberespaço e o humano que agora desponta.

2. Analisar, a partir de propostas do campo da semiótica e das teorias da complexidade e, ainda, a partir de um modelo cognitivo de memória criativa, a plausibilidade de um imperativo que se imporia a todos os sistemas semióticos, a saber: Significar.

3. Por fim, propor, a partir do quadro esboçado, uma perspectiva afirmativa para a dinâmica semiótica em jogo no Ciberespaço.

\section{O Ciberespaço ${ }^{5}$}

Das muitas transformações que as tecnologias últimas vêm possibilitando as condições de aparecimento de um espaço cognitivo e 
comunicacional conhecido hoje como Ciberespaço, lançou uma série de questões a pensadores de diferentes áreas, tais como da antropologia, da sociologia, da psicologia, das neurociências, apenas para citar algumas. Nestas áreas pensa-se, particularmente, a interação do humano com este espaço, a emergência de novos modelos de sociabilidade, especulando quais transformaçôes cognitivas, comunicacionais, éticas, afetivas, dentre outras, podem estar em curso. Como observou o sociólogo André Lemos, o Ciberespaço é um 'não-lugar', uma 'uropia' onde devemos repensar a significação sensorial de nossa civilização baseada em informações digitais, coletivas e imediatas."

O termo Ciberespaço aparece primeiramente na obra de fiç̧ão cientifica Neuromancer, em 1984, do escritor William Gibson, designando um espaço paralelo, não físico, onde as relações comunicacionais e cognitivas são marcadas por uma imediatez e por uma dimensão lúdica possibilitadas pelo desenvolvimento das infotécnicas.

Duas perspectivas de compreensão para o Ciberespaço são sugeridas por Lemos ${ }^{7}$ : a realidade virtual - ambientes ficcionais em três dimensões criados a partir de aparatos tecnológicos onde um usuário mergulha, tendo seu corpo, seus sentidos e suas faculdades cognitivas estimuladas. E como o conjunto das infovias. autoestradas eletrônicas que possibilitam a interligação de redes de computadores em escala planetária, como a internet, os BBSs, videotextos etc. ${ }^{8}$

Como uma zona virtual contígua ao mundo real, o Ciberespaço deve ser pensado como a disponibilização de uma camada eletrônica onde se promovem operações semióticas, complexificando o universo das experiências humanas.

Uma das características mais intrigantes deste novo espaço está no seu aspecto não físico, não concreto, imaterial, à medida em que traduz o que eram átomos em bits", viajando na forma de impulsos eletrônicos pelas grandes infovias, isto é, pelas auto-estradas da informação.

O ciberespaço, desconhecendo fronteiras nacionais ou continentais, desconsiderando assim espaços físicos e geográficos, desde que estejam garantidas as conexões infotécnicas reticulares, apresentará, também, como uma de suas características, uma dimensão de aterritorialidade.

Se os cabos telefônicos e satélites são objetos concretos e necessários para a transmissão dos dados entre diferentes subjetividades ${ }^{10}, 0$ conteúdo, as mensagens transmitidas são invisiveis, existindo em es- 
tado de potência, podendo ser atualizados quando um computador é ligado e passa a tratar tais informações.

A velocidade vertiginosa com que se pode acessar as informações que circulam no Ciberespaço funda uma nova percepção temporal esteiada na experiência de instantaneidade: um tempo instante quase zero" .

A possibilidade de acessar, alterar, torcer, rearranjar e disponibilizar o produto elaborado de forma imediata, promovendo trocas simultâneas entre regiões planetárias as mais distantes, propicia o aparecimento de novas estratégias cooperativistas e possibilita que cada usuário aproprie-se e torne adequado a si quaisquer informações obtidas na rede. Este último aspecto dá ao Ciberespaço uma dimensão hipertextual, onde o leitor passa a atuar como co-autor e ator do próprio texto lido, à medida em que intervém, modificando partes de um texto que se mostra vivo, costurando junto ao tecido pluricultural o seu contexto, as suas vivências, suas idiossincrasias, em um jogo que não conhece demarcações de início ou fim. ${ }^{12}$

162 É importante ressaltar que todos estes aspectos dão possibilidades às redes de comunicação telemáticas de uma dimensão massiva e ao mesmo tempo interativa que não se verificava nos meios de comunicação mais conhecidos e familiares (tv, rádio, jornais etc.).

Os aspectos que demonstram a dimensão massiva da rede podem ser constatados nos números que a envolvem. De um número inicial de quatro computadores conectados em um experimento militar norteamericano, em 1970 (a Arpanet), a Internet tem hoje algo em torno de 3,2 milhões de computadores interligados, devendo explodir, nos próximos anos, para centenas de milhões de usuários. ${ }^{13}$

Aspectos da interatividade do Ciberespaço podem ser vislumbrados dentre uma infinidade de exemplos, como no fazer jornalístico, onde já existem jornais que ouvem seus clientes na hora de fazer suas pautas de matérias, atentos às sugestões de matérias, enfoques, nomes de personalidades a serem entrevistadas etc. Possibilita, ainda, edições personalizadas para seus diferentes leitores através da comunicação on-line. ${ }^{. t}$

Todas essas transformações comunicacionais criam oportunidades novas para o exercício humano produzindo sociabilidades outras, variando desde o reaparecimento de práticas culturais adormecidas até 0 comparecimento de novas formas de relacionamentos.

A prática epistolar, por exemplo, é retomada com intensidade nes- 
se contexto no qual enviar uma carta tornou-se tão mais fácil e rápido. ${ }^{15}$

Práticas místicas e de renascimento de um encantamento do mundo podem ser vistas em comunidades virtuais tais como ravers ou zippies que exercem um tecnopaganismo, misturando no Ciberespaço espiritualidade, teosofia, hermetismo e medicina natural com a tecnologia de ponta, arma eficaz para uma plena transmissão das suas mensagens. ${ }^{\prime \prime}$

O anonimato que possibilita conversas em chats sem comprometer pessoas, possibilita exercícios relacionais bastante singulares. Personalidades ficcionais podem ser assumidas, nutrindo experiências existenciais que nos espaços urbanos não-virtuais se dariam com mais dificuldades. Um indivíduo pode, então, possuir muitas identidades, com variações de sexo, quereres, posicionamentos políticos, ideológicos etc. Abre-se um leque de possibilidades lúdicas para o exercício humano que poderão afetar a personalidade do internauta, dando-lhe novos contornos. Dois exemplos, apresentados por Palacios, podem ser bastante ilustrativos quanto a este ponto. O primeiro, extraído de Rheingold:

"Os deficientes fisicos, que em geral têm dificuldades em fazer amigos, vibram ao descobrir que nas comunidades virtuais eles são tratados como sempre quiseram ser tratados, ou seja, como seres pensantes, comunicadores de idéias, tradutores de sentimentos e não como corpos que tem esia ou aquela maneira bizarra de andar ou de falar (ou mesmo impossibilidade de falar ou andar)."

O segundo exemplo é apresentado ao falar da participação de pessoas em MUDs, um tipo de teatro interativo (RPG-Role Playing Games) encenado, neste caso, via Internet.

Ao encarnar, por exemplo, a Rainha Fracine, uma heroina romântica porém decidida, numa comunidade de RPG, o Dr. Evandro Teixeira Vialle (que na "vida real" é um respeitável cirurgião-dentista especializado em endodontia, com consultório em São Paulo), está interagindo com sua própria imagem ficcional, uma vez que cabe a ele construir eletronicamente a personagem e tomar as decisões de Francine. Porém, para ser bem sucedido no Jogo, o Dr. Vialle deve tomar as decisões a partir não de sua lógica da "vida real", mas da lógica de Francine em seu mundo de fantasia. E deve tomá-las numa situação de interação com dezenas ou centenas de outros avatares ficcionais construidos por pessoas localizadas nas mais diversas partes do mundo, que tém o ciberespeço como ponto de encontro!" 
Pode-se, pois, pensar o Ciberespaço como um veículo novo para a entrada e a produção de desejos em todas as suas instâncias, ganhando possibilidades de realizações de forma virtualizada, realizações não menos importante para a produção de significações subjetivas do que se realizadas de forma concreta.

O que aqui está se observando é que a materialidade das coisas fisicas podem servir como obstruções para a realização de muitos dos desejos humanos (por exemplo, voar sem avião, andar sobre a água, atravessar paredes etc.), que assim, sequer ganham manifestações na consciência. Tais obstruções funcionariam como forças repressivas de ordem primária, dos desejos. ${ }^{18}$

Da mesma forma, obstáculos morais, religiosos, políticos e ideológicos perdem a sua força por estarem em um meio no qual não podem ser impostos, mas, consultados, visitados, explorados. Deste modo, a experiência de se viver, ainda que por alguns poucos momentos, exercendo uma outra subjetividade marcada por outras referências que não aquelas que atuaram nas gêneses psico-afetivas, pode produzir efeitos clínicos, no sentido de promover deslizamentos significantes para uma dada subjetividade que se via cristalizada em referências que eram tomadas, por mecanismos recalcantes, como imóveis e permanentes.

O Ciberespaço, ao permitir de forma virtual a realização de desejos, funciona como um enorme laboratório existencial, que vem revelar dimensões de uma humanidade que a tudo deseja. É como se os processos desejantes se atrevessem mais a um comparecimento, uma vez que condições obstacularizantes tivessem se enfraquecido.

O sistema ciberspaço/humano estaria, pois, revelando dimensões de uma humanidade vocacionada para a mistura, para a criação radical, para a instabilidade, para a reinvenção de si mesma, para o infinito. Permitindo o exercício exacerbado de diferentes humanidades, revela o quão humano são os sintomas, por mais variados e bizarros que possam parecer.

Neste sentido o sistema em questão poderá produzir um efeito $\mathrm{cli}^{\prime}$ nico no seio desta própria humanidade emergente, à medida em que deixa transparecer que a humanidade em questão acata cada vez menos imposições globais no gerenciamento e exploração de seus desejos, sejam imposições fisicas, comportamentais, ideológicas, políticas, religiosas etc.

Isto já se tornou visível quando se volta a atenção para os diferentes tipos de comunidades virtuais existentes no Ciberespaço, para to- 
dos os temas imagináveis de listas de discussões, para as facilidades de se criar a partir de dispositivos infotécnicos que permitem consultas rápidas e/ou apropriações e colagens de imagens e de sons, para as novas formas de se fazer negócios, enfim, para toda série de transformações telemáticas que afetam de diferentes formas o ser do humano.

Quer-se agora, entretanto, uma vez expostos aspectos gerais do Ciberespaço, verificar a plausibilidade de uma hipótese anunciada a de que há uma lei que se impõe a todas as coisas do Univerșo como um imperativo: Significar! A análise do funcionamento de diferentes sistemas semióticos poderá revelar outras perspectivas para o entendimento do Ciberespaço.

\section{Significar!}

Quando se reflete sobre a origem e o desenvolvimento do Universo, as dinâmicas e processos físicos, o aparecimento da vida e das diferentes espécies vegetais e animais pensa-se nas possibilidades de princípios e de ordenações que encadearam múltiplos episódios capazes de gerar tudo aquilo que há.

Mesmo admitindo processos de destruição e de desorganização, instabilidades e oscilações assistemáticas como episódios casuísticos que rompem ordens e promovem o caos como hiatos em séries genéticas progressivas, a ciência se erigiu a partir da possibilidade do conhecimento de leis e de princípios que permitem a explicação de diferentes fenômenos do Universo, promovendo leituras deterministicas destes mesmos fenômenos, levando o ideal laplaceano da previsibilidade aos últimos estertores.

Hoje, depois da adoção dos fenômenos caóticos como uma importante área de estudos científicos ${ }^{19}$, a ciência continua sua marcha, menos arrogante no que diz respeito ao ideal laplaceano e assumindo discretamente o fim das certezas universais. Seja como for, continua a buscar o entendimento de ordens (os estudos do caos continuam sendo estudos de processos de ordenações atípicas) e de como as coisas se articulam e se comportam, enfim, de como se relacionam.

Quando conjectura-se aqui a possibilidade de um imperativo que se imporia a todos os objetos do Universo exigindo a produção de significação por eles próprios, quer-se com isto pensar que para que haja a instauração de quaisquer formas de ordem é necessário que as coisas se relacionem a partir de leis que orientem suas operações.

Se admite-se que o Universo evolui a partir de leis da termodinâmica, pode-se aventar a hipótese de que essas leis funcio- 
nem como uma gramática que dá sentido aos diversos elementos que estão em jogo na dinâmica evolutiva, isto à medida em que produz, com uma certa eficiência, sinais que são interpretados pelos elementos em questão e que, a partir disto, os fazem agir de maneira fundamentalmente homogênea, esteiados na leitura produzida do texto termodinâmico. Esta idéia seria visualizada no fato dos elementos comportarem-se de uma certa maneira e não de outra. Um sentido, uma significação se impõe.

Reconhece-se que a conjectura que aqui se apresenta pode ser pensada a partir do campo da semiótica, particularmente como processos de semioses que, neste caso, não estariam restritos ao campo dos sistemas vivos. Tal compreensão encontra eco exatamente naqueles pensadores que querem expandir os limites dos processos de semiose para a esfera do não vivo. Tal possibilidade foi demonstrada pelo físico Jorge de Albuquerque Vieira ${ }^{20}$, que faz coro junto a outros pensadores que aventam a mesma perspectiva, tais como Santaella, Merrell, Anderson e colaboradores.

A semiótica, embora com a restrição de algumas escolas, ganhou hoje em dia dimensões que extrapolam o campo humano, podendo ser vista como uma área de investigações que se estende da semiótica da arquitetura, da biossemiótica ou da cartossemiótica até a zoossemiótica, podendo, assim, ser definida de maneira bastante genérica como a ciência dos signos e dos processos significativos (semiose) na natureza e na cultura. ${ }^{2 !}$

Entretanto, os autores recém citados já especulam há algum tempo sobre a possibilidade de expansão dos limites da semiótica, questionando a validade de limitá-la ao domínio dos sistemas vivos.

Conforme Vieira, a discussão acerca dos limites da semiótica para universos não vivos encontra a resistência de um grupo de pensadores que insistem que a definição peirceana triádica de signo exige um interpretante (junto dos elementos representamen e objeto) e isso, por sua vez, exigiria a presença de um sistema vivo. Dentro desta perspectiva processos semióticos não ocorreriam antes do surgimento da vida no Universo e, assim, nem mesmo uma proto-semiótica seria admitida. ${ }^{22}$

Vieira contra-argumenta, a partir das mesma referências peirceanas:

[...] o problema é saber o que Peirce queria dizer com 'mente' $e$ interpretante' ou que limites colocou (se os colocou) aos conceitos de 'vivo' e 'não vivo'. (...) E se os conceitos de vida, mente, significação, 
entre outros, forem dilatados em seus alcances, o processo de semiose pode efetivamente ser encontrado em todo o Universo.

Vieira aponta ainda o caminho encontrado por alguns dos autores que defendem que processos de auto-organização seriam responsáveis pelos processos de semiose no reino dos não vivos. Citando Santaella, Vieira incita à especulação das possíveis relações entre a teoria peirceana dos signos e os processos de auto-organização. Escreve, então:

É assim, na visão peirceana, que encontramos a possibilidade de conciliar o vivo e o não vivo, já que a sua semiótica é ' tão geral a ponto de fornecer elementos para compreender e descrever semioses de qualquer ordem, sejam elas físicas, orgânicas, humanas ou cosmológicas(...) para evidenciar a continuidade existente entre a mente humana e outros processos movidos por um propósito que incluem. como exibindo alguma forma de mentalidade, entre outros, o comportamento de microorganismos, a evolução biológica e até mesmo o crescimento de cristais. Tal postulação entra em perfeita sintonia com a atual teoria das estruturas dissipativas, desenvolvida por Prigogine, onde a causação final estaria na tendência para a ordem que Prigogine descobre até mesmo em tipos bem rudimentares de reações químicas... Todo processo autogerativo é processo de semiose.' (Santaella, 'A assinatura das coisas':54-80)"

A aposta que este texto faz, buscando a compreensão de diferentes processos de significação, embora próxima à perspectiva apresentada por Vieira em sua hipótese sobre a plausibilidade de se estender o campo da semiose para o mundo não vivo e, ainda, lançando mão de alguns recursos teóricos comuns tal como a teoria das complexidades, como a da auto-organização, optará por um caminho próprio, inspirado em alguns estudos cognitivos contemporâneos, particularmente naqueles que versam sobre as potências de uma função memória que revele sua dimensão criativa. ${ }^{23}$

Ao concluir esse percurso, buscar-se-á pensar a possibilidade de suspensão de algumas antinomias que comparecem nos discursos acerca dos processos cognitivos e comunicacionais contemporâneos e, por fim, propor uma perspectiva afirmativa para se pensar o Ciberespaço.

\subsection{Ordens, Desordens e Auto-organização:}

A perspectiva que se desenvolverá agora parte das idéias da teoria da auto-organização, passando pelo entendimento da complexidade, 
com o intuito de demonstrar como a idéia de memória, revelada em sua dimensão criativa, pode e deve ser requerida para se pensar os diferentes processos de significação.

A teoria da organização a partir dos ruídos, ou ordem por complexidade, foi o arcabouço intelectual que permitiu o desenvolvimento da hipótese de uma teoria da auto-organização. Os primeiros passos desta história foram dados a partir de estudos realizados por von Neumann, Winograd e Cowan acerca da possibilidade de construção de autômatos, seguidos por concepções de nomes tais como von Foerster, Atlan, Ashby, Eigen, Prigogine, dentre outros. ${ }^{24}$ Suas raízes, entretanto, são mais antigas.

Toda a problemática que envolve os estudos sobre ordens e desordens pode ser simplificada tendo como referencial um princípio que rege a evolução dos sistemas naturais que é o segundo princípio da termodinâmica, do qual deriva-se a idéia de entropia. Este princípio postula que qualquer sistema físico (entendido da maneira mais simplificada como uma porção qualquer de elementos agrupados), es-

168 tando entregue a si mesmo e fechado, isto é, sem realizar trocas com o seu meio, forçosamente evoluirá para um estado de maior desagregação molecular. Quando tal evolução atingir uma situação de homogeneidade ou de equilíbrio haverá, então, em um aparente paradoxo, um estado de desordem máxima..$^{25}$

Este aparente paradoxo se explica quando se entende a desordem em questão como uma relação estatística que possibilita pensar o sistema, isto é, as partículas submicroscópicas que o constituem, espalhadas ao máximo no seu meio, portanto, desorganizado.

Um bom exemplo para clarificar esta situação seria a fumaça de um cigarro se espalhando por uma sala fechada. No estado de máxima dispersão da fumaça, ao mesmo tempo em que há uma homogeneidade entre o ar e a fumaça, pode-se pensar que a fumaça (o sistema em questão) estaria maximamente desorganizado (comparado com as formas organizadas quando a fumaça era visualizada.). Poderia-se dizer, ainda, que este sistema estaria em estado de entropia máxima.

Esta homogeneidade perfeita corresponderia, conforme Atlan, a uma equiprobabilidade de se encontrar, no caso apresentado, moléculas da fumaça por todo o espaço no qual ela se espalhou. É para esse estado de entropia máxima que o sistema evolui até atingir, por fim, o equilíbrio. 
Os processos de desorganização podem ser entendidos, então, como processos nos quais os sistemas têm sua entropia aumentada a um valor máximo. Contrariamente, pensar processos de organização significa que um sistema tem sua entropia mantida em níveis mínimos.

Cabe aqui a pergunta: como alguns sistemas conseguem manter a entropia em baixos niveis e assim fazerem emergir estados organizados? A resposta imediata seria - desde que se constituam como sistemas abertos, isto é, como sistemas capazes de promoverem trocas de matéria e de energia com o seu meio. Pois, sabe-se desde Schrödinger, em 1948, que é possivel, teoricamente, haver uma diminuição da entropia dentro de um sistema aberto com o proporcional aumento da entropia do ambiente. ${ }^{20}$ Os sistemas vivos são exemplos de tais sistemas, como também fenômenos marginais como a formação de redemoinhos estáveis na água corrente ou formas estáveis numa chima de vela ou ainda a formação de cristais em massas amorfas minerais. A questão importante agora seria: quais são as condições ou leis que possibilitam que sistemas baixem sua entropia e, assim, promovam sua auto-organização, evoluindo para um estado de maior diversidade e de complexidade?

Há duas possibilidades para que isto ocorra. Na primeira, o sistema é organizado recebendo uma série de impulsos já organizados do seu meio. Neste caso, observa Atlan, nũo há razão alguma para falar em auto-organização, pois, os impulsos externos que incidirão sobre o sistema, por serem séries de efeitos organizados, organizarão também o sistema. ${ }^{27}$ Poderia-se dizer, simplesmente, que tais impulsos são organizadores.

A outra possibilidade seria a de que os impulsos externos que agem sobre um sistema, sendo aleatórios e não organizados (para o sistema), não possam garantir organização alguma. Entretanto, se o sistema reage frente a tais perturbações e, ao invés de se desorganizar ou perecer aumenta sua complexidade e organização, tem-se um sistema que pode ser definido como auto-organizador. A propriedade de auto-organização, processos de produção de novas modalidades de ordens, estaria, desse modo, ligada à capacidade de um sistema incorporar agentes aleatórios ou ruídos em suas dinâmicas evolutivas.

O ruido, em uma definição genérica, seria o conjunto de fatores aleatórios que se distinguem da informação e que produziriam erros no sistema. Mas deixariam de ser tomados por ruidos a partir do momento em que fossem utilizados como fatores para a organização do 
próprio sistema. Dentro desta perspectiva, um sistema, vivo ou não, poderia se organizar, se auto-organizar, a partir de ruídos.

Diferentes sistemas portariam, então, graus de complexidade diferenciados conforme a capacidade de lidar com ruídos. A complexidade aqui em questão deverá ser pensada, pois, tanto como a quantidade de elementos em jogo para um dado sistema, quanto pelas posições que ocupam estes elementos nas interações com o mesmo sistema. Nesta segunda acepção (topológica) o que estaria em jogo é a propriedade de não-comutatividade dos elementos como definidora da complexidade. ${ }^{28}$ Simplificadamente isto significa que não apenas um número alto de elementos em um conjunto é definidor de complexidade como também as posições que ocupam os elementos em um dado conjunto são definidoras de complexidade.

Um sistema complexo e auto-organizado teria, pois, a capacidade de lidar não só com arranjos, mas com quantidades de variáveis aleatórias, buscando identificar padrões dentro deste universo de variáveis que são incorporadas pelo sistema, aumentando sua diversidade e sua complexidade. E por que diversidade e complexidade seriam interessantes na evolução dos sistemas? Ora, para que esses possam lidar com as permanentes mudanças e alterações do meio, para se confrontarem com mais competência com o aleatório, o que é extremamente importante, particularmente em se tratando de sistemas vivos.

H. von Foerster e Ashby falam desta importância em suas proposições. Von Foerster, o primeiro a exprimir a necessidade de um princípio de ordem a partir do ruido para explicar as operações autoorganizadoras dos organismos vivos, afirma que quando um sistema se fixa num estado particular, ele fica inadaptável, e esse estado final pode ser igualmente ruim. Ele será incapaz de se ajustar a alguma coisa que constitua uma situação inadequada. ${ }^{29}$

A lei da variedade indispensável, proposta por Ashby, se assemelha em muito às idéias de von Foerster. Resumidamente, esta lei pode ser entendida nos seguintes termos: Em um ambiente que seja fonte de diversas agressões imprevisiveis, a variedade na estrutura e nas funções do sistema é um fator indispensável de autonomia. ${ }^{30}$ Variedade esta que pode ser pensada em função do grau de complexidade do sistema.

Tais idéias podem parecer uma contradição com uma das proposições da teoria da Informação de Shannon, que postula que um dos métodos que um dado sistema pode recorrer para lutar contra o ruído, ou seja, para identificar e corrigir eventuais erros na transmissão(e 
captação) de mensagens, consistiria na introdução de uma certa redundância, isto é, uma repetição dos símbolos na mensagem. ${ }^{31} \mathrm{Ou}$ seja, se há a necessidade de uma repetição de mensagens frente a perturbações ou ruídos, como uma variabilidade pode ser importante?

Será neste ponto que a idéia de uma memória será requisitada para se pensar os diferentes processos semióticos, pois, se por um lado ela deve dar suporte para a realização da redundância, por outro lado ela deve possibilitar uma variedade indispensável para os sistemas mais complexos. A conjectura que se faz diante deste impasse é que a memória comparecerá marcada por graus diferenciados de complexidade, conforme o grau de complexidade do próprio sistema. Assim, poderá oscilar em seu funcionamento desde (no caso de sistemas de baixa complexidade) a simples função de reconhecimento (um átomo de oxigênio reconhecendo um de hidrogênio e vive-versa, por exemplo), até (nos sistemas adaptativos complexos) uma possibilidade de transcriação ${ }^{32}$ dos conteúdos mnemônicos. Trata-se, neste caso mais elevado de complexidade, de uma memória que, se permite a repetição de símbolos na mensagem por um lado; por outro, não seja excludente quanto a novas operações que possam se dar no tratamento desta informação pelo sistema. " Esta característica será o que garantirá o não fechamento do sistema, tornando-o adaptativo, uma vez que não o impediria de um possível encontro criativo com o devir, ao invés de fixar uma única maneira de lidar com o aleatório.

Traduzindo a idéia acima em outros termos, o que parece estar em jogo nas operações de significação de sistemas adaptativos complexos é a capacidade das estruturas mnemônicas se manterem, mas também de se alterarem, influenciadas por múltiplos fatores que afetam o sistema, particularmente o contexto em que se dão tais operações.

\subsection{A produção de significados como processos de organização:}

Dentro do quadro teórico que aqui se propõe, pode-se legitimar a hipótese de um imperativo tal como o significar! se impor a todas as coisas, entendendo-o como uma resposta original, diante do convite termodinâmico ao perecimento. Deflagra-se, então, uma busca de ordem por parte de todos os sistemas que há, como uma insistência na permanência, reduzindo os seus níveis de entropia e ganhando diversidade e complexidade.

Realmente, observando a evolução de todos os sistemas do Universo, o que salta aos olhos é o ganho em complexidade e diversidade que 
todos eles apresentam, dos elementos químicos às tecnologias, passando por todas as espécies minerais, vegetais e animais, embora sempre acossados pela desordem e pelo desaparecimento.

Para efeitos meramente didáticos, três possibilidades de sistemas serão consideradas e analisadas em seus processos de produção de significados.

O primeiro conjunto de sistemas, considerado de baixa complexidade, realizaria suas produções de significado sem a participação de uma memória criativa. Os processos mnemônicos aqui presentes devem ser pensados meramente como recuperação de informação, portanto, pode-se dizer que com pouca variabilidade quanto às suas possibilidades de significação. Neste modelo, as regras e princípios físicos se impõem de maneira exclusiva, fazendo com que os resultados das significações possam ser conhecidos, dentro de um quadro científico, por antecipação. Tais como os sistemas que a geraram, as significações, neste caso, serão de baixa complexidade. A título de compreensão poderíamos pensar em alguns exemplos para este modelo de sistemas: corpos em queda livre, reações químicas ordinárias, máquinas elementares tais como os motores vetoriais, fenômenos fisicos elementares etc.

O segundo grupo de sistemas admite uma complexidade mediana e, da mesma forma que o primeiro, seria portador de uma memória, mas neste caso já com dimensões criativas, ainda que de média complexidade. Suas significações ainda seriam pouco criativas quando comparadas com a última classe de sistemas. Neste caso, alguns exemplos poderiam ser: máquinas cibernéticas que já simulam alguma capacidade de inteligência, algumas classes de animais e de vegetais inferiores etc.

O terceiro grupo de sistemas, com altas taxas de complexidade, portaria uma memória altamente criativa, podendo, com isso, gerar significações ricas em diversidade, até mesmo ambíguas. Este tipo de sistema estaria, inclusive, sujeito a desagregações, frutos das próprias significações produzidas. É neste terceiro conjunto de sistemas onde se encontraria o híbrido humanidade-ciberespaço.

A lógica da produção de significados aqui apresentada poderia ser resumida nos seguintes termos: sistemas diferenciados quanto aos graus de complexidade (baixa, média e alta complexidade), portariam memórias proporcionais aos seus graus de complexidade, variando quanto aos seus processos de produção de significado, da simples possibilidade de reconhecer elementos com os quais interagem (evocar informações estocadas que permitem o reconhecimento) à possibilida- 
de de promoverem operações com os seus conteúdos mnemônicos, podendo com isso criar significações novas frente às informações com as quais interagem.

É importante, ainda, observar-se que estes últimos modelos de sistema, pela riqueza e variabilidade das suas produções semióticas, podem, por vezes, dentro do jogo da auto-organização, promover desordens no próprio sistema como um efeito de excesso de complexidade. Tais excessos poderão constituir-se em novos conteúdos para uma organização crescente em termos de complexidade, ou, em alguns casos. promover uma desorganização radical do próprio sistema.

Assim, quanto maiores as taxas de memória criativa e de complexidade, maior a possibilidade das significações produzidas serem ricas e variadas, organizando, ampliando e complexificando ainda mais o sistema. E, por outro lado, o excesso de possibilidades significantes do próprio sistema produz uma maior disponibilidade para a instabilidade e para o cuos. o que poderá, ou não, ser o recomeço do eterno jogo da auto-organização.

\section{Conclusão: suspendendo antinomias, afirmando o}

Ciberespaço como sistema semiótico hipercomplexo.

A possibilidade da assunção de um imperativo que se imporia a todos os sistemas - ordenando significa! - os aproximariam entre si, não só por conta dessa condição de inexorabilidade frente a um mesmo imperativo, mas também pelas dinâmicas dos seus funcionamentos semióticos, que exigem uma função memória comum a todos.

Se há diferenças radicais entre os sistemas, tais diferenças deverão ser pensadas em termos de graus de complexidade e não mais em termos de natureza dos sistemas. Isto poderia promover a suspensão de antinomias que insistentemente pontuam reflexões contemporâneas sobre os processos de comunicação e de cognição, tais como: mental $x$ fisico, humano $x$ inumano, virtual $x$ real.

O Ciberespaço, pensado como produto e como produtor de significações, não diferiria funcionalmente de outros sistemas, sejam estes produzidos ou não por híbridos humano-lecnologia. Sua função básica, como outros sistemas semióticos, é propiciar um substrato mnemônico de conteúdos (informações) para a realização de significações. Neste caso, porém, regido pela dimensão criativa desta memória, poderá produzir significações radicalmente novas, trans-criadas, que seriam, por tantas vezes, tomadas como irreais, fantásticas, ilusórias, falsas; enfim, adjetivos que buscam marcar a distância des- 
tas para com outras significações menos complexas ou, simplesmente, menos novas e mais comuns. Não seria, talvez, por este caráter incomum que as significações transcriadas seriam vistas, muitas vezes, como estranhas ao humano?

Se o Ciberspaço pode ser pensado como uma extensão cognitiva e comunicacional de uma nova humanidade - mais uma, dentre tantas que já surgiram -, a complexidade deste sistema humano/ tecnológico deverá ser pensada como hipercomplexa e, assim, capaz de significações tão radicalmente novas que poderão soar como nãosignificações. Tais não-significações poderiam ser pensadas tanto como o vertiginoso movimento de acúmulo de informações disponíveis _ promovendo o excesso _ que tantas vezes saturam o ambiente no qual se navega, quanto por todos os tipos de mensagens não significadas pela distância cultural destas para com múltiplos outros contextos.

Com o comparecimento dessas não-significações, tem-se a proliferação de ruídos e toda uma sorte de aleatoriedades que podem instau-

174 rar momentos ou zonas de caos no Ciberespaço, afetando diversas subjetividades das mais diferentes formas.

Por outro lado, como demonstrado pelas teorias da auto-organização, a complexidade e a enorme variabilidade de que é dotado o sistema, poderá promover a digestão destes ruídos, aumentando ainda mais a variabilidade e complexidade do próprio sistema, fazendo emergir novas formas de ordem. Assim, as subjetividades que interagem entre si ganhariam novos elementos para significar as nãosignificações e a si mesmas.

Vê-se, então, que essas não-significações tornam-se significações, tais como os ruídos tornam-se informações para aqueles tipos de sistemas que estão aptos para lidar com o aleatório.

Pode-se pensar, pois, que todas as dimensões não-significantes que estão em jogo neste momento no Ciberespaço e na cibercultura, sejam os alvos de todas as concepções que enxergam neste novo cenário cognitivo e comunicacional o desaparecimento do humano, o assassinato do real, greve dos acontecimentos, vazio do sentido, grau-zero de comunicação ${ }^{3 t}$, imagens que escapam à consciência, incapacidade de avaliar o presente, um labirinto para animais de laboratório ${ }^{35}$. Não conseguiriam ver, ainda, tais concepções, as não-significações como parte de um processo de significação em andamento, comum a todos os sistemas semióticos complexos. 
As formas para a produção de significados em sistemas hipercomplexos poderão exigir novas modalidades de tempo, irão se dar por vias novas, exigindo e selecionando novas competencias cognitivas das subjetividades que fazem parte deste sistema. Todo este processo, já em andamento, não possui mapeamentos, estratégias claras, acordos prévios, códigos instituídos e coletivamente aceitos. Eis o sistema em estado de guerra. Conta-se com um conjunto de saberes, armas e vivências, mas também com o aleatório, com os fluxos desorganizados de turbas coléricas ou apavoradas. É um cenário assustador? Pode ser. Mas os mais importantes avanços tecnológicos e, conseqüientemente, culturais para a humanidade tem vindo, insistentemente, destes cenários apocalípticos pré e pós-guerras. ${ }^{36}$

A memória atuante neste sistema, qual o próprio sistema, é hipercomplexa. Apresenta, pois, aos extremos as duas possibilidades de complexidade anunciadas: excesso de informações ou de padrões mnemônicos e múltiplas possibilidades de arranjá-los. São destas múltiplas possibilidades de arranjos, aliás, que brotam as não-significações que irrompem no Ciberespaço. A transcriação, portanto, só é possivel a partir destas condições garantidas pelas memórias complexas: excesso de informações e disponibilidade para rearranjar tais informações de diferentes maneiras.

O processo de transcriação sempre parte das memórias disponiveis que são re-arranjadas em novos modelos a partir de demandas contextuais. As não-significações devem ser pensadas como estes jogos de uma memória hipercomplexa, criativa, em ação no Ciberespaço. São, pois, (trans)criadas a partir de outras significações que, mais adiante, poderão ser lidas como novas significações, entretanto, quando se está no meio deste processo semiótico, tudo pode parecer excessivamente estranho, sem sentido, nulo em significação. É somente com a lógica dos processos auto-organizantes que se pode legitimar processos como os descritos como processos de significação.

A tradição ocidental, norteada pelo princípio aristotélico da não contradição, quer, quando pensa os processos de significação, clareza, exatidão, linearidade. Encontra, nos sistemas pouco complexos. Aumentando a complexidade dos sistemas tais processo serão obscuros, inexatos, não lineares, mas continuam em marcha. Todas as perspectivas teóricas que se recusam a ver este funcionamento que se dá através de pólos aparentemente excludentes, perdem a possibilidade de participar do fluxo inventivo da evolução. 
Todo o processo de produção de sentidos dentro do Ciberespaço, se pode soar sombrio, não deve ser visto como diferente de tantos outros processos auto-organizantes que se dão em todo o Universo, capazes de incorporarem o diferente, o desorganizador e, em alguns momentos, aparentarem-se extremamente sem sentido, caóticos.

Os processos semióticos do Ciberespaço são condizentes e próximos, assim, a tantos outros passos dados pelo Universo, na sua infinita jornada semiótica, dança arḍorosa entre o caos e a ordem.

\section{Referências Bibliográficas:}

ATLAN, Henry. Entre o Cristal e a Fumaça. Rio de Janeiro, Jorge Zahar Ed., 1992

. L'organization Biologique et la Théorie de L'information. Paris, Hermann, 1972. . Les Théories de Complexité. Aoutour de L'Ouvre d'Henry Atlan, Atas do Colóquio de

Cerisy-la-Salle de 1984, sob a direção de F. Fogelman-Soulié. Paris, Le Seuil,1991.

BAUDRILLARD, J., A ilusão do fim ou A greve dos acontecimentos. Lisboa; Terramar, 1992.

CAMPOS, H., A Arte no Horizonte do Provável; e outros ensaios. São Paulo, Perspectiva, 1977.

CARDOSO, C., Entrevista concedida ao programa TIC - Tecnologias de Informação e Cultura, (http://radio.pinheiroguimaraes.br L

CASTELLS, M., A Era da Informação: Economia, Sociedade e Cultura. Vol. I: A Sociedade em Rede; São Paulo, Paz e Terra, 1999.

EDELMAN,G. M., A Biologia do Conhecimento - As raizes do conhecimento. Lisboa, Instituto Piaget, 1995.

GELL-MANN, M., O quark e o jaguar - As aventuras no simples e no complexo. R.J., Rocco, 1996.

GLEICK, J., Caos. A Criação de uma Nova Ciência. Rio de Janeiro, Ed. Campus, 1991

LANDOW, G., Hypertext. The Emergence of Contemporary Critical Theory and Technology. Mass.,The John Hopkins University Press, 1994. 
LEMOS, A., As Estruturas Antropológicas do Cyberespaço 14/06/98 (http://www.facom.ufba/pesq/cyber/lemos/estrcyl.html); $10 /$ $\underline{12 / 98}$

LÈVY, P. As Tecnologias da Inteligência. O futuro do Pensamento na Era da Informática. Rio de Janeiro, Ed.34 . 1993.

. Inteligência Coletiva - Por uma antropologia do ciberespaço. São Paulo. Ed. Loyola, 1998.

LEWIN, R., Complexidade - A vida no limite do Caos. R.J., Rocco, 1996

MAGNO,M.D., Pedagogia Freudiana. Rio de Janeiro, Imago, 1993.

MALUF,U.M., entrevista concedida a Vinícius A. Pereira; Programa PLEC

Pesquisas, Leituras e Estudos sobre a Complexidade, rádioweb $\mathrm{Pi}$ nheiro Guimarães, (http://radio.pinheiroguimaraes.br)

NEGROPONTE, N., A Vida Digital; S.P., Cia das Letras, 1995.

NÖTH,W., Panorama da Semiótica - De Platão a Peirce. S.P.; Annablume, 1995

PALACIOS, M. Normalização de Documentos online. Modelos para uma padronização. 08/08/96 (http://www.facom.ufba/pesq/ cyber/norma.html) 10/12/98

Modens, Muds, Bauds e Ftps :aspecios da comunicação no final do milenio.; (http://www.facom.ufba/pesq/cyber/palacios/ modens.html); 10/12/98.

PEREIRA. V.A., O humano e a teoria das Estranhezas. Dissertação de Mestrado apresentada ao Instituto de Psicologia da U.F.R.J. Rio de Janeiro, 1996.

Mnemonise e Criação: O papel da memória na Ecologia Cogitiva; ; ' Texto apresentado na VII Compós, no GT Comunicação e Sociedade Tecnológica. S.P., 1998.

. Linhas mnêmicas, imaginárias e simbólicas esboçando a face humana. Artigo publicado em Logos - Comunicação e Universidade, Publicação da UERJ, N. ${ }^{\circ}$; R.J. 1998

ROSENFIELD, I., A invenção da Memória: uma nova visão do cérebro., R.J., Ed.34,1994

SCHEPS,R., (org.) O Império das Técnicas. S.P.; Papirus, 1996.

VIEIRA, J. de A., Semiótica, Sistemas e Sinais. Tese de Doutorado: Comunicação e Semiótica,.PUC-S.P./1994. 
VIRILIO, P., Guerra Pura. A militarização do cotidiano. S.P., Ed. Brasiliense, 1984.

. O espaço crítico e as Perspectivas do Tempo Real. Rio de Janeiro; Ed. 34,1993.

\section{Notas}

1 Conforme abordou-se em Mnemonise e Criação: O papel da memória na Ecologia Cogitiva: A morte do homem pode ser entendida como o soçobrar de um modelo cognitivo que dominou o século XIX e boa parte deste, onde um sujeito, sede inarredável da razão onipotente, dirigia-se aos objetos, podendo apreender os princípios gerais das coisas, explicando o próprio mundo e a si mesmo... Cf. em Pereira, V.A.; Texto apresentado na VII Compós, no GT Comunicação e Sociedade Tecnológica.

2 Ver Pereira,V.A.; O humano e a teoria das Estranhezas. Dissertação de Mestrado apresentada ao Instituto de Psicologia da U.F.R.J. Rio de Janeiro, 1996.

3 Pode-se pensar aqui, por exemplo, em propostas tais como as de um J. Baudrillard e as de um P. Virilio. Ver, por exemplo, respectivamente, em $A$ ilusão do fim ou $A$ greve dos acontecimentos; e $O$ espaço critico e as Perspectivas do Tempo Real.

4 Neste caso pode-se citar, como exemplo, as propostas de um pensador como P. Lèvy. Ver, por exemplo, em As tecnologias da Inteligência - O futuro do pensamento na era da informática e/ou $A$ Inteligência Coletiva - Por uma antropologia do ciberespaço.

5 Para um aprofundamento deste conceito ver a excelente compilacão bibliográfica sobre o tema que a Faculdade de Comunicação da Universidade Federal da Bahia disponibiliza dentro do site Pesquisa sobre o cyberespaco, pesquisa esta coordenada pelos Profs. Marcos Palacios e André Lemos. (http://www.facom.ufba.br/pesq/ cyber/)

6 Como ainda não há uma norma consensualmente aceita para citacões de documentos online, adota-se aqui as orientações dadas por Marcos Palácios em Normalização de Documentos online. Modelos para uma padronização. 08/08/96 cf. em (http:// www.facom.ufba?pesq/cyber/norma.html);10/12/98

Para a nota 6 ver em Lemos, A.; As Estruturas Antropológicas do Cyberespaco 14/06/98 (http://www.facom.ufba/pesq/cyber/lemos/ estrcyl.html): 10/12/98 
7 Cf. Lemos, A.; op.cit.

8 Para uma melhor compreensão destes e de outros termos comuns ao universo da comunicação telemática, ver em Palácios, $M_{\text {. }}$ Modens, Muds, Bauds e Ftps:aspectos da comunicação no final do milênio.; (http://www.facom.ufba/pesq/cyber/palacios/ modens.html L; 10/12/98.

9 Negroponte, N., A Vida Digital.

10 Aqui usada em um sentido maior, para além da visão de mundo ou das particularidades psico-afetivas de um indivíduo, próximo daquele apresentado por Lèvy: ... um coletivo pensante homens-coisas, coletivo dinâmico povoado por singularidades atuantes e subjetividades mutantes... Cf. em Levy, P.; As Tecnologias da Inteligência; p.11

11 Em entrevista concedida ao programa T.I.C. - Tecnologias de Informação e Cultura, na radioweb Pinheiro Guimarães, Cláudio Cardoso afirma que a expressão tempo real, para expressar uma idéia da imediatez com que se acessam às informações online, não lhe agrada muito por insinuar que haveria um outro tempo não real, ou falso, em oposição ao real. Prefere. pois, o termo imediatez. Concordando em termos gerais com esta interpretação de Cardoso, optou-se, aqui, pela expressão tempo instante quase zero, a fim de manter afastada a antinomia real x irreal, bem como para tentar traduzir a velocidade vertiginosa do processo em questão. Cf em TIC-Tecnologias de Informação e Cultura, programa da rádioweb Pinheiro Guimarães produzido e apresentado pelos professores Simone Pereira de Sá e Vinícius A. Pereira; (http:/l radio.pinheiroguimaraes.br)

12 Cf. Landow, G.; Hypertext. The Emergence of Contemporary Critical Theory and Technology.

13 Cf., por ex., em Castells, M. A Sociedade em Rede, p. 375. Maiores informações sobre os números do crescimento do ciberespaço podem ser obtidas em sites tais como Nerwork Wizards (http://www.nw.com), International Data Corporation (http:// www.idcresearch.com), Instituto de Tecnologia da Georgia (http://www.cc.gatech.edu/gvu), dentre outros. Para dados sobre 0 crescimento da Internet no Brasil ver em Comitê Gestor Nacional (http://www.cg.org.br); ver, ainda, para a consulta de dados sobre o perfil do internauta brasileiro, pesquisa desenvolvida pelo Cadê em parceria com o Ibope disponível no endereço (http:// www.cade.com.br/cgi-bin/cadeibope).

14 Cf. Palacios, ibid. 
15 Cf. Palacios, ibid.

16 Cf. Lemos, A., ibid.

17 Cf. Palacios, ibid.

$18 \mathrm{Cf}$, , por exemplo, nas idéias apresentadas pelo psicanalista M.D.Magno em Pedagogia Freudiana.

19 Vide Gleick, J.; Caos - A invenção de uma nova ciência.

20 Vieira, J.A. Semiótica, Sistemas e Sinais; Tese de Doutorado em Comunicação e Semiótica - PUC/S.P.

21 Vide Nöth, W . Panorama da Semiótica - De Platão a Peirce.; p.19.

22 Vieira, J.A. op.cit. p.110.

23 Cf. Rosenfield, R., A invenção da memória.

24 Cf. Atlan, H.; Entre o Cristal e a fumaça. p. 38-46.

25 Cf. Atlan, H.; op.cit. p. 138.

18026 Cf. Atlan, H.; ibid., p. 138.

27 Cf. Atlan,H.; ibid; p. 139.

28 Cf. entrevista de Ued M. Maluf concedida ao programa PLECPesquisas, Leituras e Estudos sobre a Complexidade, na rádioweb Pinheiro Guimarães, (http://radio.pinheiroguimaraes.br)

29 Cit. por Atlan, H. ibid.; p. 38.

30 Cf. Atlan, H. ibid.; p. 39.

31 Cf. Atlan, H. ibid; ; 39.

32 Conforme observou-se em Mnemosine e Criação: O papel da memória na Ecologia Cognitiva; Pereira,.V.A.: Este neologismo, o verbo transcriar, foi proposto por Haroldo de Campos ao falar sobre o seu processo de tradução. Explica, então, que em vez de simplesmente traduzir, isto é, substituir uma língua por outra, o trabatho do tradutor deve se pautar em um processo de criação a partir de um material já escrito, por ser impossivel uma substituição de uma lingua por outra sem perda de informação. Assim transcriar implica em trabalhar com uma informação básica, mas modificála de alguma forma. Algo se mantém da informação original, mas, também, algo se transforma nesta mesma informação. Cf. Campos, H.; A Arte no Horizonte do Provável; e outros ensaios. p.100119. 
33 Quanto a esta última dimensão da memória, trata-se de, à luz de proposições oriundas do campo das ciências da cognição (particularmente de Edelman.(3. A Biologia do (onhecimento), pensar a memória como uma faculdade fortemente criativa que, se possui uma divida para com um referente. este comparece como que um sombreado, uma evanescência, como um rastro, porém, necessário, visto ser impossivel criar o novo a partir do nada. Cf. em Pereira, V.A. em obras ciladas.

34 Cf. Baudrillard, J., op.cit.

35 Cf. Virilio, P.. op.cit. e Guerra Pura. A militarização do cotidiano.

36 Cf. Scheps, R.; O Império das Técnicas. 




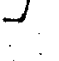


A revista contracampo permanece fiel ao propósito de estabelecer aberto diálogo entre as mais diferentes abordagens nos campos da comunicação contemporânea, conformando assim o necessário espaço para os debates transdisciplinares.

Neste quarto número se consolida a idéia da publicação de artigos de alunos, no sentido de se manter a completa integração dos corpos docente e discente do curso de Mestrado em Comunicação, Imagem e Informação da Universidade Federal Fluminense. 